\title{
Farm and bench
}

\author{
Climate change could compromise food security over the coming century. Scientists working towards \\ mitigation and adaptation have to win over those who work on the land.
}

The vulnerability of humans and ecosystems to climate change has firmly entered the research agenda. According to the second part of the Fifth Assessment Report (http://go.nature.com/jj6TE4) from the Intergovernmental Panel on Climate Change (IPCC), published on 31 March 2014, the number of publications on adaptation, impacts and vulnerability doubled between 2005 and 2010. With this broadened scientific base, food production is emerging as one of the key focus points for urgent action. Now is a good time for climate scientists to reach out to farmers and ranchers worldwide, to help them assess potential climate-change impacts on their own businesses, and engage them in the search for solutions.

Ecosystems around the globe are responding to climate change, as exemplified by shifts in the activity and geographic range of numerous species in freshwater, marine and terrestrial environments. Food production may be particularly hard-hit: climate change is expected to affect not only the quantity of available plant-based food, but also its nutritional quality, that is, the protein, starch and micronutrient content of the produce. Yields of wheat, rice and maize are projected to decline in temperate and tropical regions around the globe if local temperatures rise around $2{ }^{\circ} \mathrm{C}$ or more above late-twentieth-century levels. And the quality of cereal crops and forage is expected to fall in response to a rise in atmospheric carbon dioxide concentrations. The livestock industry could be directly affected: less protein, combined with warmer temperatures, could mean smaller and less healthy animals. Faced with these potential problems, ranchers in the US are starting to take note of climate change (page 322 ).

Although a consensus has yet to be reached on the extent to which climateinduced shifts in agricultural production will modify food prices, events over the past decade suggest that markets may indeed be sensitive to weather fluctuations. Numerous factors are thought to have contributed to recent hikes in global food and cereal prices, including high demand for biofuel crops and fluctuating oil prices. However, in many cases these spikes have

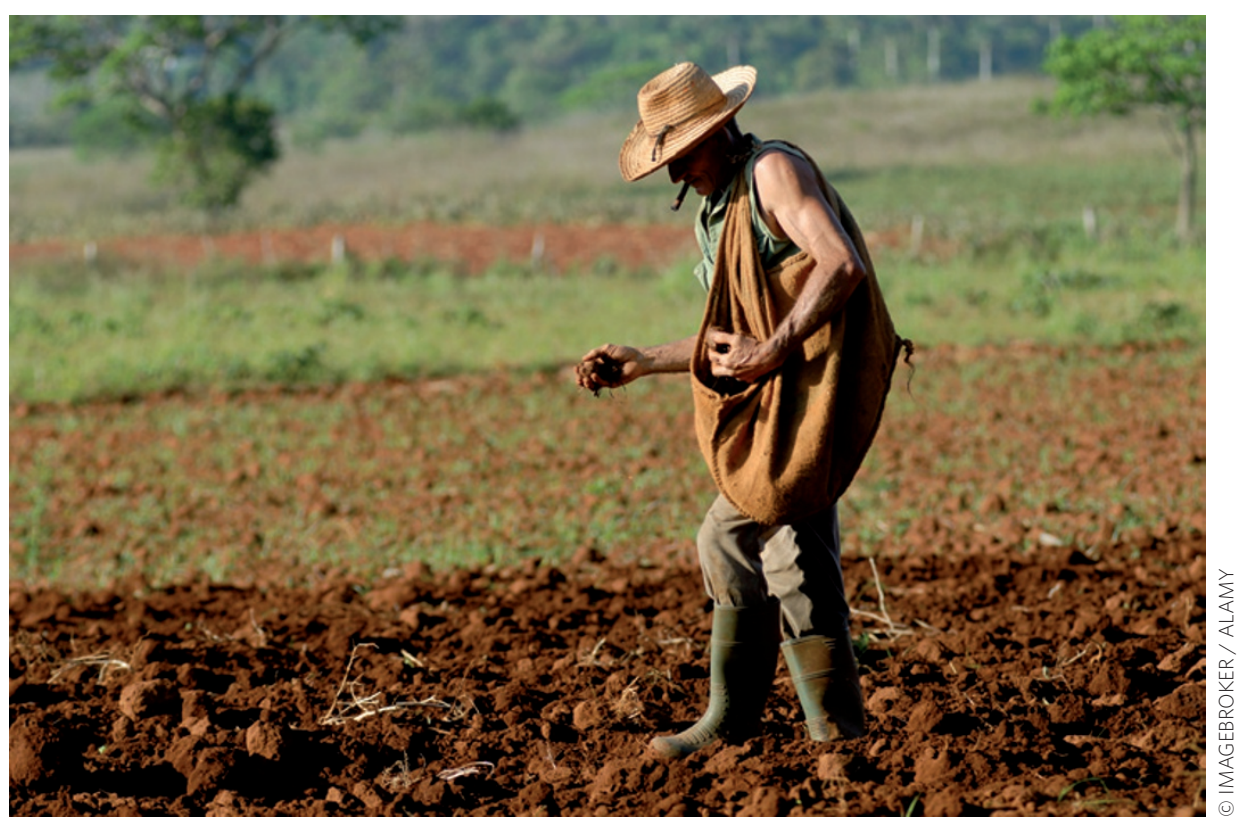

followed extreme weather events in key food-producing countries, hinting at an environmental trigger. Developing nations may grow increasingly vulnerable to future food price volatilities as they are selling off large swathes of agricultural land to more affluent societies, rendering their own people dependent on food imports and hence global market forces (page 324).

When it comes to meeting the challenge of feeding the Earth's future inhabitants, the adaptation of agricultural practices holds some promise. Planting times could be adjusted to match region-specific shifts in the duration of the growing season which may lengthen, or in some cases shorten due to end-of-season droughts. Crop cultivars could be adapted to cope with the specific stresses a given region is likely to face. And, more drastically, croplands could be expanded polewards onto previously inhospitable tracts of land, made more amenable to cultivation through warming. Regions in Russia, Scandinavia and Canada hold promise in this respect. Overall, however, the benefits of adaptation measures are likely to vary strongly with region and crop type.

But agriculture is not only the victim of climate change. Industrialstyle food production, in particular, contributes significantly to greenhouse gas emissions and pollution. Many of the approaches to damping down agricultural emissions discussed so far - such as reducing excess fertilizer use - would be relatively straightforward to carry out (Nature Geosci. 4, 277-278; 2011). However, remedies must be closely tailored to the region and agricultural system in hand. The impacts of adding biochar to croplands, for example, can turn from benefit to harm, depending on local conditions and the type of biochar used (page 326).

Whether food production can keep pace with a burgeoning global population will depend on whether agricultural systems can be modified to cope with the rising temperatures and increased prevalence of droughts, floods and other extreme weather events that are projected to ensue. Now that the impacts of a changing climate are becoming increasingly clear, action must be taken at a local level. Key to the success of these strategies will be the ability of the scientific community to win over farmers and ranchers to the cause. Only with their full support and their knowledge of the land can both adaptation of agriculture and mitigation of its climate impacts succeed. 